\title{
TRPC3 as a key player in electrical remodelling of atrial myocardium

\author{
Zora Saad ${ }^{1}$, Petra Eder ${ }^{1}$, Klaus Zorn-Pauly ${ }^{2}$ and Klaus Groschner*1
}

\author{
Address: ${ }^{1}$ Department of Pharmacology and Toxicology, Institute of Pharmaceutical Sciences, University of Graz, 8010 Graz, Austria and ${ }^{2}$ Institute \\ of Biophysics, Center of Physiological Medicine, Medical University Graz, 8010 Graz, Austria \\ Email: Klaus Groschner* - klaus.groschner@uni-graz.at \\ * Corresponding author
}

from $14^{\text {th }}$ Scientific Symposium of the Austrian Pharmacological Society (APHAR)

Innsbruck, Austria. 2I-22 November 2008

Published: 5 November 2008

BMC Pharmacology 2008, 8(SuppI I):A3 I doi:|0.| |86/|47|-22I0-8-SI-A3 I

This abstract is available from: http://www.biomedcentral.com//47I-22I0/8/SI/A3 I

(c) 2008 Saad et al; licensee BioMed Central Ltd.

Recent evidence suggests involvement of transient receptor potential (TRP)-related cation channels in cardiac physiology and pathophysiology, with TRPC3 as one potential key player in cardiac hypertrophy. It has been suggested that TRPC3 is upregulated in hypertrophy development and contributes to $\mathrm{Ca}^{2+}$ signals that govern pathological remodelling. As TRPC proteins form nonselective cation channels, we hypothesized that these molecules determine not only $\mathrm{Ca}^{2+}-$ mediated gene expression but also excitability and basic electrical properties of the myocardium in pathological states. We utilized the patch clamp technique to characterize the electrical remodelling associated with enhanced TRPC3 expression in cardiac myocytes. The murine HL-1 atrial cell model, which was found to express both TRPC 3 and TRPC6 at low levels along with typical signalling partners of TRPC proteins such as $\mathrm{Na}^{+} / \mathrm{Ca}^{2+}$-exchanger- 1 and $\mathrm{Ca}_{V} 1.2$, was modified to overexpress a functional YFP-TRPC3 fusion protein. TRPC3 over-expressing cells displayed substantially altered electrical properties even in the absence of TRPCactivating stimuli, as evident from a significant shortening of basal action potential duration and impaired frequency-dependent adaptation of action potential shape. Action potential-clamp experiments as well as mathematical modelling attempts were performed to delineate the consequences of TRPC 3 overexpression and to analyze the mechanisms of TRPC3-mediated electrical remodelling in the heart. Our results suggest a pivotal role of TRPC channels in cardiac electrical remodelling associated with maladaptive hypertrophy. 